
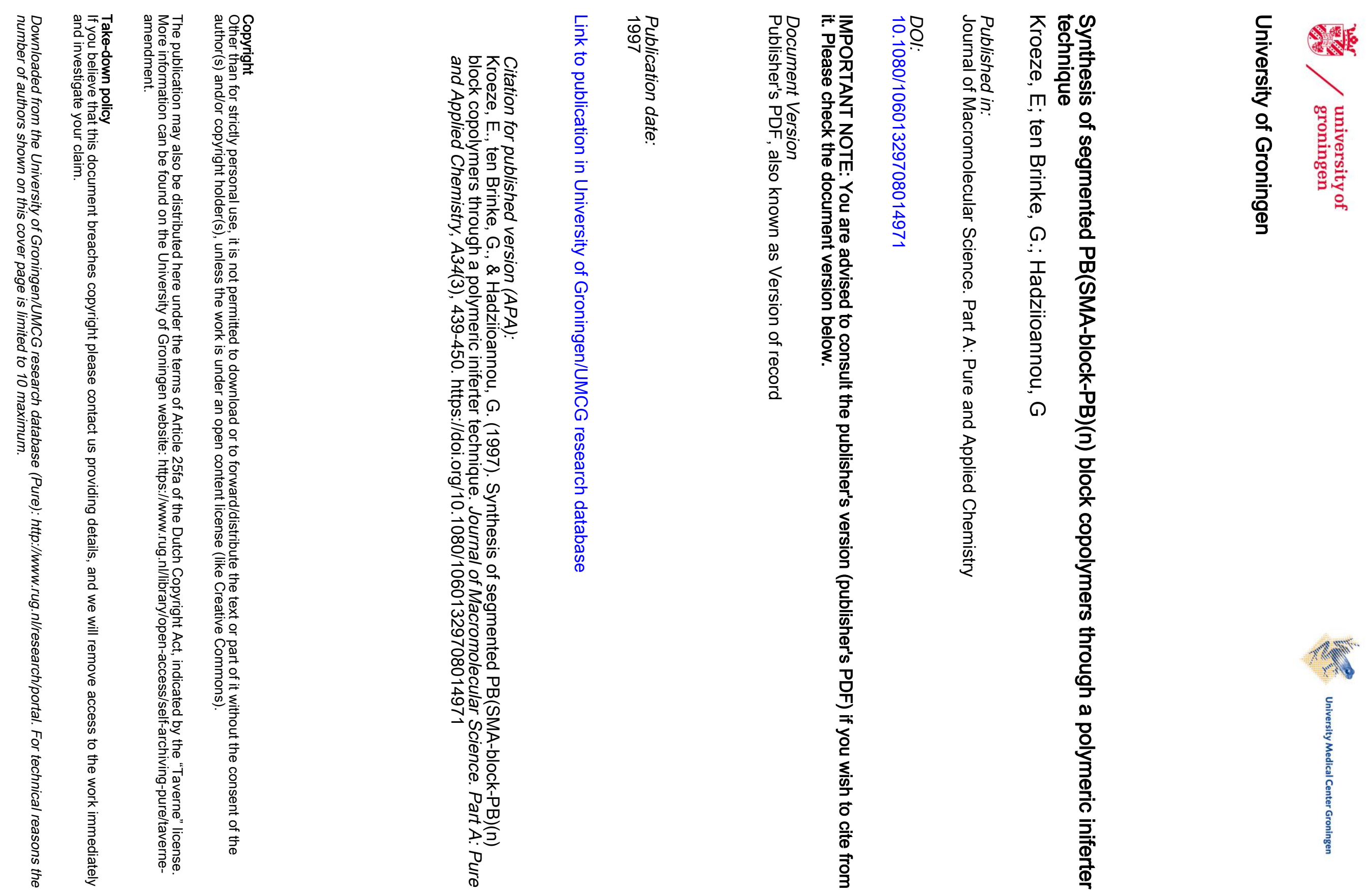
J.M.S.-PURE APPL. CHEM., A34(3), pp. 439-450 (1997)

\title{
SYNTHESIS OF SEGMENTED PB(SMA-block-PB) BLOCK COPOLYMERS THROUGH A POLYMERIC INIFERTER TECHNIQUE
}

\author{
E. KROEZE, G. TEN BRINKE,* and G. HADZIIOANNOU* \\ Department of Polymer Chemistry \\ Materials Science Center \\ University of Groningen \\ Nijenborgh 4, 9747 AG Groningen, The Netherlands
}

Key Words: Carboxy-terminated polybutadiene; Polymeric iniferter; Copolymerization; Styrene; Maleic anhydride; Segmented block copolymer; Reactive compatibilizer; Composition; Differential scanning calorimetry

\begin{abstract}
A technique is described for the synthesis of segmented block copolymers of polybutadiene and poly(styrene-co-maleic anhydride) through a polymeric therma iniferter based on polybutadiene, which was used as an initiator for the thermal copolymerization of styrene and maleic anhydride. The polymeric iniferters and block copolymers were characterized by GPC, elemental analysis, 'H NMR, FT-IR spectroscopy, and differential scanning calorimetry. The compositions and SMA block lengths in the block copolymer could be regulated by varying the polymeric iniferter concentration. The maleic anhydride content of the SMA blocks was regulated by adjusting the monomer feed composition. The synthesized block copolymers are very promising materials for use as compatibilizers for nylon-based blends, in particular for blends of nylon with ABS or polyethylene.
\end{abstract}




\section{INTRODUCTION}

Polymer blends provide the advantage that the properties of the material can be controlled by varying the type and quantity of polymers in the mixture [1,2]. In this way the attractive properties of both blend components can be combined in one material. The actual fabrication of polymer blends, however, poses significant challenges. Most polymer pairs are immiscible, leading to phase separation of the blend components into distinct, macroscopic domains. Often such blends show poor mechanical properties, particularly those related to ductility. A significant part of this problem is poor force transfer between component phases. To improve the mechanical properties of the resulting material, block copolymers may be added to the mixture [3-6]. If they localize at the interface between the immiscible polymers, they lower the interfacial tension and they disperse and stabilize the morphology of the polymer blend. Consequently, these blends show improved mechanical properties.

An attractive alternative is to form the block or graft copolymer in situ during melt blending via interfacial reaction of added functionalized polymers. The control of morphology in multiphase blends through reactive compatibilization has been addressed in several publications [7-11]. In many cases this approach seems to be the method of choice for compatibilization.

The work described here is motivated by the current interest in compatibilized nylon-based blends. Nylons are an attractive class of polymers for engineering applications. However, they have a number of deficiencies such as brittleness, high moisture sorption, and poor dimensional stability. By blending with other plastics, like PPO [poly(2,6-dimethyl-1,4-phenylene oxide)] [12, 13], ABS (acrylonitrile/butadiene/styrene copolymer) [14-19], polyolefins [8-10], polycarbonate [20] or rubbers $[7,11,21]$, these deficiencies can be improved. However, these blends show poor mechanical properties in general and therefore they have to be compatibilized.

Currently, compatibilized blends of ABS and nylon show great industrial interest. A particularly attractive feature of nylons is their capability of reactive coupling to other polymers through the amine or carboxylic end groups that may be present, and possibly the amide linkages themselves. So, by choosing a functionalized polymer which can react with nylon and miscible with the other blend component, improved mechanical properties of the blend can be obtained by reactive compatibilization.

This paper describes the synthesis of segmented block copolymers of polybutadiene (PB) and poly(styrene-co-maleic anhydride) (SMA). This is a new type of block copolymer which could have great potential as a reactive compatibilizer for nylon-based blends. In these block copolymers the maleic anhydride moieties in the SMA blocks are the reactive units toward the amine end groups of nylon chains.

Copolymers of styrene and maleic anhydride of the appropriate composition are known to be miscible with styrene-co-acrylonitrile copolymers [22-25], which is an important feature when used for compatibilization of $\mathrm{ABS} /$ nylon blends because ABS can be viewed as a rubber-modified SAN copolymer. In Fig. 1 the compositional ranges are shown for miscibility between SAN and SMA copolymers. Because the SAN blocks in ABS generally contain $25 \mathrm{wt} \%$ acrylonitrile, the SMA copolymer should have a maleic anhydride content of approximately $20-35 \mathrm{wt} \%$ to ensure miscibility with the SAN phase of ABS. 


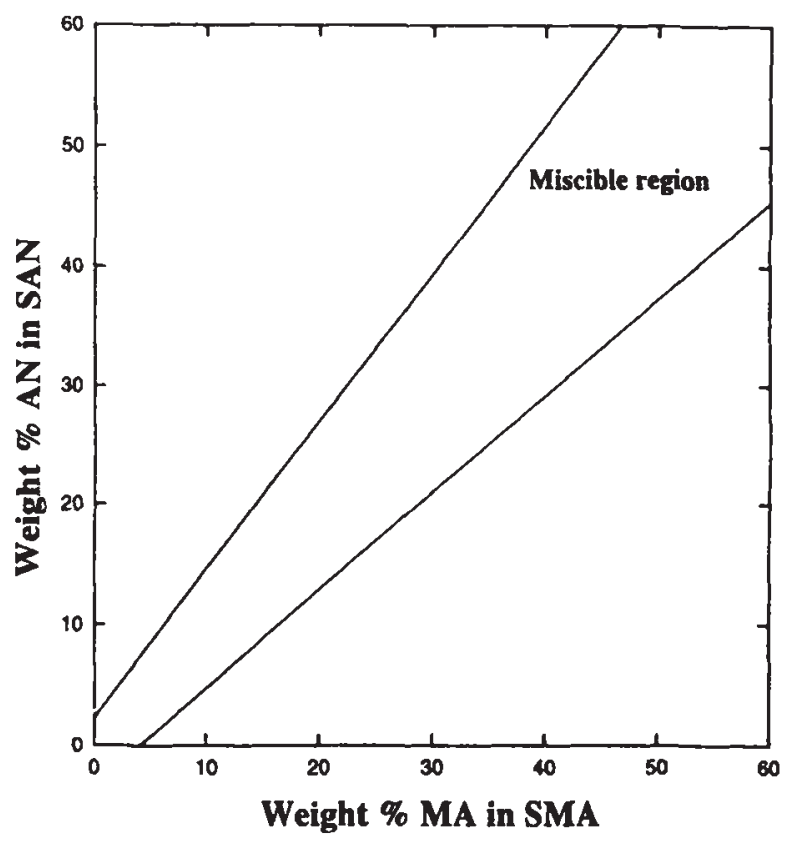

FIG. 1. Miscibility map for blends of SAN and SMA copolymers.

So, when used for compatibilization of ABS/nylon blends, the polybutadiene blocks serve to ensure miscibility of the block copolymer with the rubber part of ABS, while the SMA copolymer blocks (with the appropriate composition) are miscible wit the SAN phase of ABS and react with the nylon chain ends.

Also, after hydrogenation of the butadiene blocks, this type of block copolymer could be applied for reactive compatibilization of blends of polyamides with polyolefins. In that case the MA content of the block copolymers has to be considerably lower (1-2 wt \%) than when used for compatibilization of ABS/nylon blends. In that case the hydrogenated polybutadiene blocks are miscible with the polyethylene phase, while the maleic anhydride groups of the SMA blocks will react with the amino end groups of the nylon chains. Finally, these block copolymers might be used as rubber-toughening agents for polyamides.

So far, random or alternating copolymer blocks, like SAN (random copolymer of styrene and acrylonitrile) or SMA (alternating copolymer of styrene and maleic anhydride), have only been incorporated in a copolymer by grafting them on a polymer chain, e.g., EPDM (ethylene propene diene monomer rubber) [26-28]. These graft copolymers proved to be efficient compatibilizing agents for many different incompatible polymer mixtures.

Because anionic polymerization techniques are not suitable for the synthesis of random or alternating copolymers, we considered a free-radical technique by use of iniferters as the most promising method for our purposes. The term "iniferter" was given to certain free radical initiators with simultaneous chain transfer properties and polymer radical termination by way of a primary radical. The term was coined by Otsu et al., $[29,30]$ who found tetraalkyl thiuram disulfides to exhibit 
these properties. In the case of photopolymerization this leads to a pseudo-living process, while in a thermal polymerization the irreversibility of the termination step (formation of $\mathbf{C}-\mathrm{S}$ bonds) prevents a living process. Otsu et al. also published results on $A B$ and $A B A$ block copolymer containing random and alternating copolymer sequences by the iniferter technique [31].

We applied a method developed by Nair and Clouet [32-35] to prepare a thermal polymeric iniferter $(P I n)$ based on polybutadiene. Previously we reported the synthesis of segmented PB(PS-block-PB) and PB(SAN-block-PB) ${ }_{n}$ block copolymers based on this method [36]. The latter block copolymers proved to be very efficient compatibilizers for LDPE/PVC blends [37]. In this work the synthesized polymeric iniferter was used to prepare segmented block copolymers of polybutadiene and SMA of various compositions by copolymerization of styrene and maleic anhydride (MA), initiated by the synthesized polybutadiene-iniferter.

\section{EXPERIMENTAL}

\section{Matorlals}

Styrene was purified by vacuum distillation from finely powdered $\mathrm{CaH}_{2}$ prior to use. Maleic anhydride (Merck) was recrystallized twice from dry chloroform and was used immediately afterward.

\section{Synthesis of Polymeric Inlferter Based on Polybutadiene $\left(M_{n}=10,200\right)$}

The synthesis of the polymeric iniferter was performed as described in a previous publication [36].

\section{Synthesis of Segmented Block Copolymers}

The required amount of polymeric iniferter was placed in a small ampule under nitrogen atmosphere. Styrene and maleic anhydride were added, and after the polybutadiene had dissolved in the monomer mixture, the ampule was placed in a thermostated oil bath. During the copolymerization the mixture was stirred continuously. The block copolymers precipitated on formation. (These observations are consistent with a previous publication by Hill et al. [38], who reported that for bulk copolymerizations of styrene and maleic anhydride at $60^{\circ} \mathrm{C}$, initiated by benzoyl peroxide, polymer precipitated for polymerizations with a monomer feed in the range $50-97.5 \%$ styrene.) After the required polymerization time the mixture was cooled down, dissolved in tetrahydrofuran, and precipitated directly into methanol. After a second precipitation from tetrahydrofurane into methanol the obtained block copolymer was collected, washed with boiling petroleum ether (bp $80-120^{\circ} \mathrm{C}$ ) to remove residual maleic anhydride, and dried in vacuo at $40^{\circ} \mathrm{C}$ for at least 24 hours.

\section{Analyses}

'H-NMR and "C-NMR spectra were recorded on a Varian Gemini-200 spectrometer, using tetrahydrofuran-d8 as a solvent and internal standard. GPC measurements were performed on a Spectra-Physics 1000 system equipped with a Visco- 
tek H502 viscometer and a Shodex RI-71 refractive index detector coupled to a Dawn light-scattering apparatus, using THF as the eluent and PS standards for calibration. IR spectra were recorded on a Mattson Instruments FT-IR spectrometer. Differential scanning calorimetry thermograms were recorded on a PerkinElmer DSC 7, using a heating rate of $10^{\circ} \mathrm{C} / \mathrm{min}$.

\section{RESULTS AND DISCUSSION}

\section{Synthesis and Characterization of Polybutadiene-Based Iniferter}

A polymeric iniferter ( $\mathrm{PIn}$ ) was synthesized from a dicarboxy-terminated polybutadiene $\left(M_{\mathrm{n}}=10,200, D=1.65\right)$. The latter was first transformed into the diacylchloride-terminated polymer using phosphorus pentachloride (see Scheme 1). This compound was reacted with piperazine, providing secondary amine end groups. Finally, the polymeric iniferter was prepared by coupling the piperazine end groups with carbon disulfide, causing an increase in molecular weight by chain extension.

Further characteristics of the polymeric iniferter and the synthesis thereof were described previously [36]. From the molecular weights of the prepolymer $\left(M_{\mathrm{n}}\right.$ $=10,200)$ and corresponding polymeric iniferter $\left(M_{\mathrm{n}}=26,500\right)$, an average number of 2.5 PB units per chain was calculated for the polymeric iniferter. In this work we used the synthesized polymeric iniferter as an initiator for the thermal

1.<smiles>O=C(O)[Pb]C(=O)O</smiles>

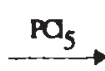

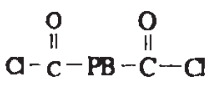

2.<smiles>O=C(Cl)[Pb]C(=O)Cl</smiles>

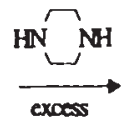<smiles>O=C(C(=O)N1CCNCC1)N1CCNCC1</smiles>

3.
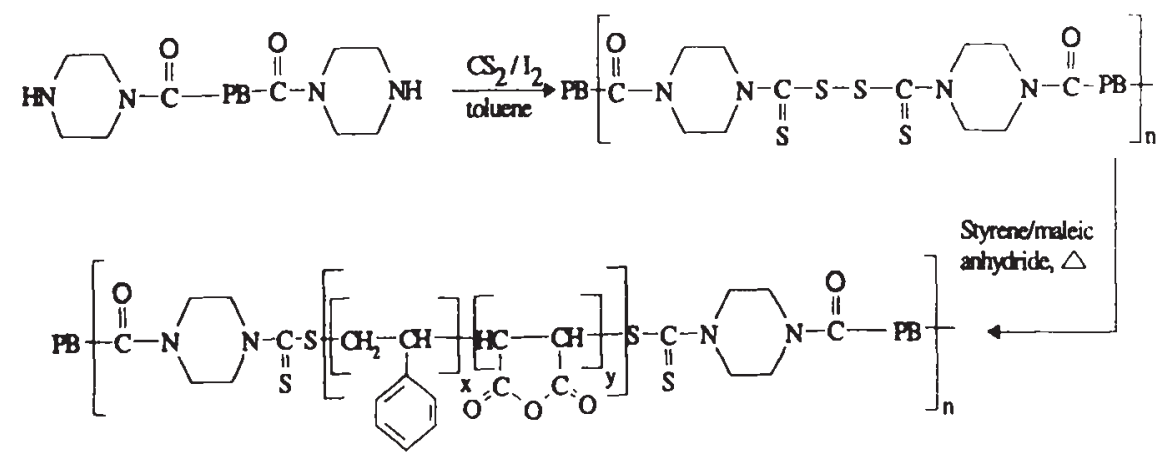

SCHEME 1. Synthesis of segmented PB(SMA-block-PB) ${ }_{n}$ block copolymers by copolymerization of styrene and maleic anhydride, using the polybutadiene iniferter as an initiator. 
copolymerization of styrene and maleic anhydride. We will designate the polymeric iniferter as PIn $=10200$ in the remainder of this publication.

\section{Synthesis and Characterization of Segmented PB(SMA-block-PB)n Block Copolymers}

The copolymerization of styrene and maleic anhydride, initiated by the polymeric iniferter, occurs via an insertion mechanism between the disulfide linkages in the prepared polybutadiene iniferter. As in any free-radical copolymerization, the length of the poly(styrene-co-maleic anhydride) blocks decreases with increasing iniferter concentration in the system. By varying the PB-iniferter concentration in the system, block copolymers with different SMA block lengths and compositions could be synthesized (see Table 1).

The determination of the block copolymer composition could not be done simply by ${ }^{1} \mathrm{H}-\mathrm{NMR}$ calculation and therefore it was calculated from a combination of both elemental analysis and ${ }^{1} \mathrm{H}-\mathrm{NMR}$ data. The maleic anhydride content of the block copolymers was calculated from the oxygen content of the block copolymers, determined with elemental analysis. Because the $\mathrm{CH}_{2}$ resonance peaks of the polybutadiene blocks overlapped with the resonance peaks owing to styrene and maleic anhydride $\mathrm{CH}$ and $\mathrm{CH}_{2}$ protons (1-4 ppm), as can be seen in Fig. 2, it was impossible to determine the maleic anhydride content of the SMA blocks by ${ }^{1} \mathrm{H}-\mathrm{NMR}$ calculation.

The polybutadiene content of the block copolymers was calculated from the found nitrogen content (nitrogen atoms originating from thiuram disulfide groups and piperazine end groups of the polybutadiene iniferter) in the block copolymers, while the styrene/butadiene ratio was calculated from ${ }^{1} \mathrm{H}-\mathrm{NMR}$ spectroscopy (the total butadiene content could not be determined from ${ }^{1} \mathrm{H}$-NMR for the same reasons as described above). The ' $\mathrm{H}$-NMR calculation of the butadiene/styrene ratio was done by integration of the $\mathrm{CH}$ resonance peaks of the polybutadiene blocks (see Fig. 2) and the aromatic resonance peaks of the styrene. The total block copolymer composition could be calculated from the butadiene/styrene ratio in the block copolymer together with the maleic anhydride content of the block copolymers found by elemental analysis. The combined data resulted in a fairly accurate determination of block copolymer compositions. The eventually calculated polybutadiene content was found to be in good agreement with the value obtained from the nitrogen content of the block copolymer. The determined block copolymer compositions were used to calculate styrene and maleic anhydride conversions, as well as polymeric iniferter consumptions.

Table 1 shows that the MA content in the SMA blocks of the block copolymer is much higher than that in the monomer feed mixture. This is a result of the highly alternating tendency in the radical copolymerization of MA with styrene. In Fig. 3 the composition of the copolymer block $\left(F_{\mathrm{MA}}\right)$ is plotted versus monomer feed composition $\left(f_{M A}\right)$ for the bulk copolymerization initiated with PIn-10200. This figure shows that the MA content of the SMA blocks reaches 50 mol\% very rapidly. Even a MA content in the monomer feed of 5-10 mol\% gives a MA content in the resulting alternating copolymer of $30-40 \mathrm{~mol} \%$. This is a similar behavior as reported earlier for benzoyl-peroxide-initiated copolymerizations of styrene and maleic anhydride [38-40]. Because maleic anhydride is a powerful electron acceptor, it 


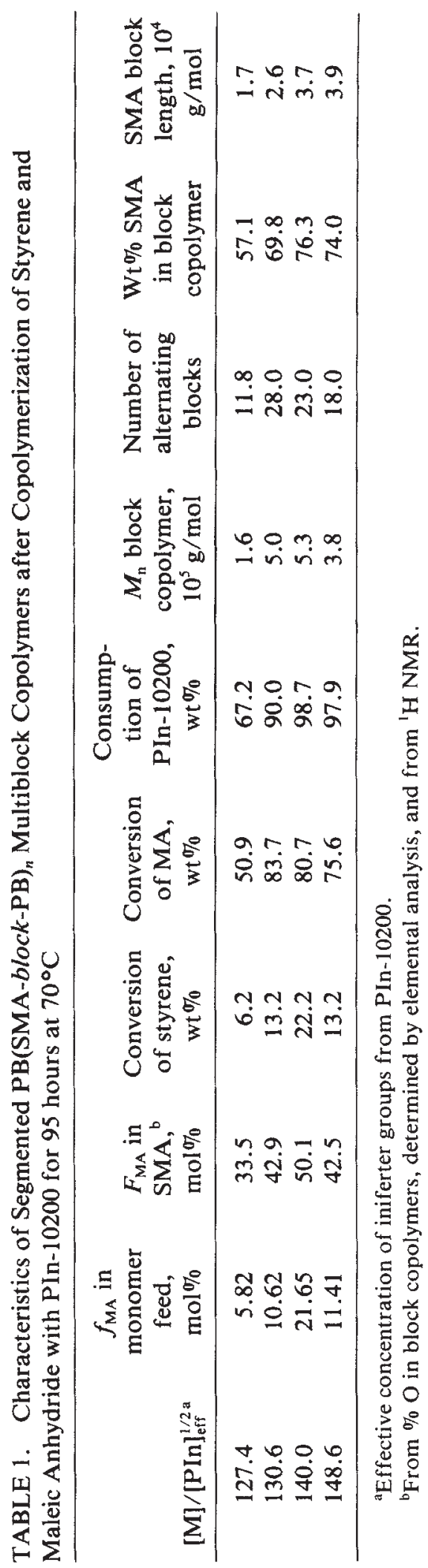




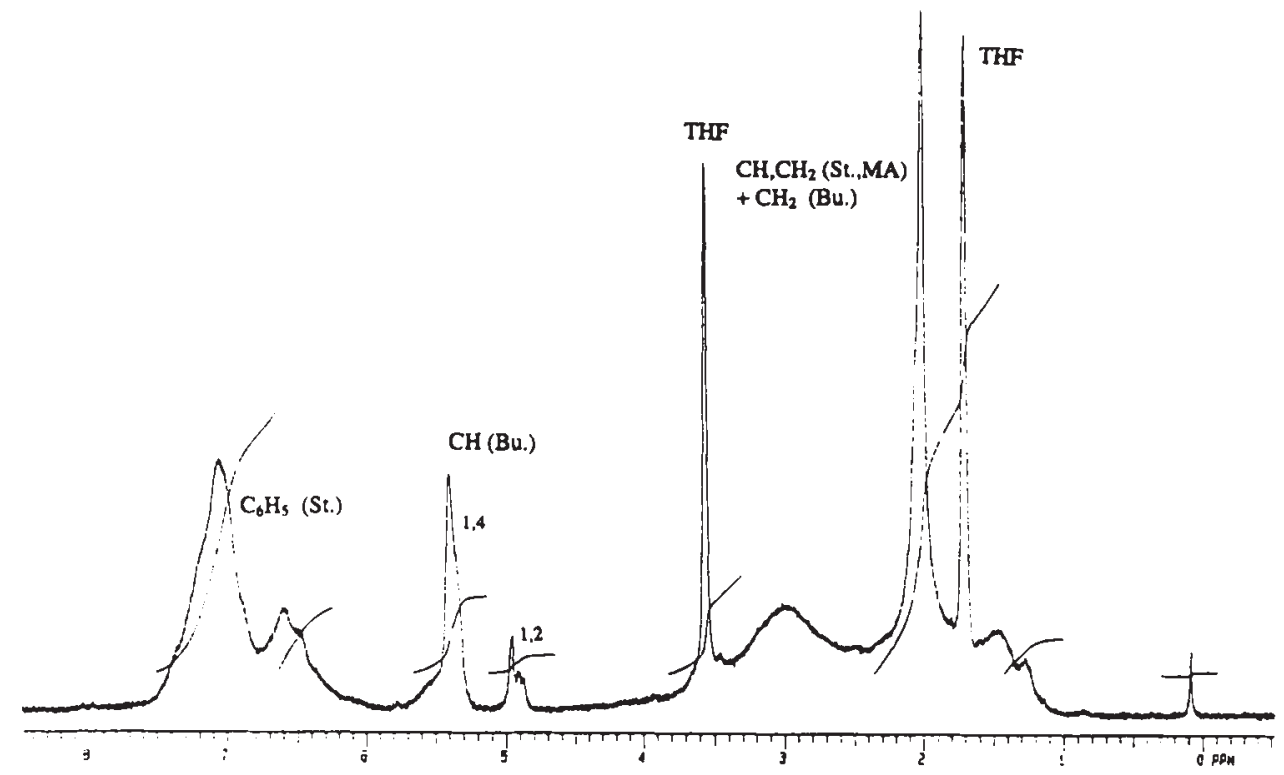
ymer.

FIG. 2. Typical ${ }^{1} \mathrm{H}-\mathrm{NMR}$ spectrum of a segmented PB(SMA-block-PB) ${ }_{n}$ block copol-

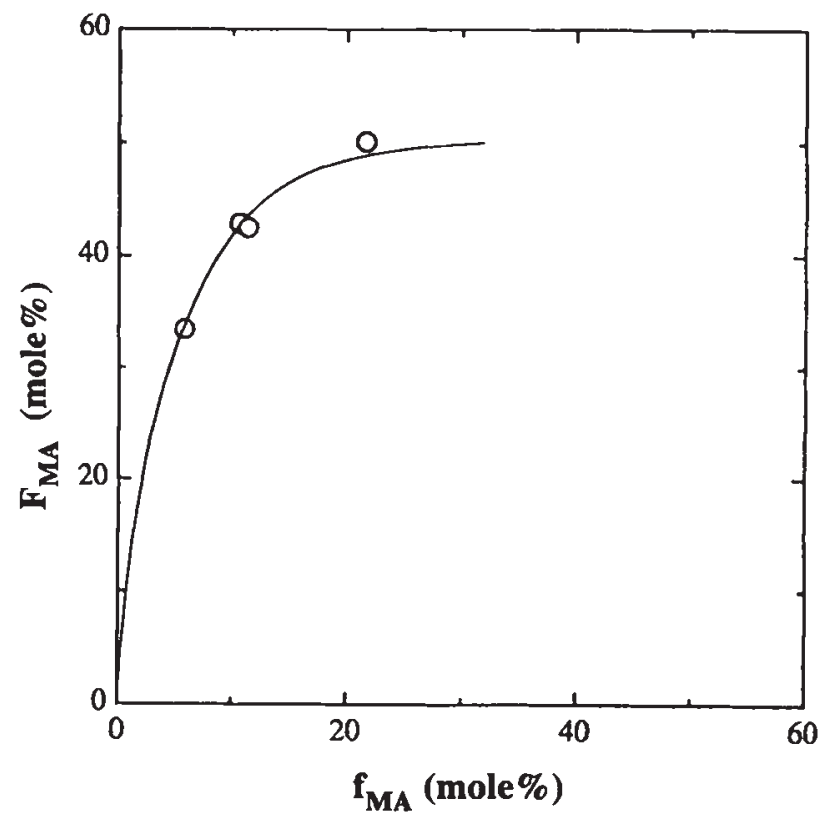

FIG. 3. Copolymer block composition $\left(F_{\mathrm{MA}}\right)$ versus monomer feed composition $\left(f_{\mathrm{MA}}\right)$ for the bulk copolymerization of styrene and maleic anhydride at $70^{\circ} \mathrm{C}$, using PIn- 10200 as an initiator. 
will enter into a copolymerization reaction very easily, but it homopolymerizes very difficultly. Because of the highly alternating nature of MA, contents of more than 50 mol\% MA cannot be attained for copolymerizations of maleic anhydride and styrene.

The number of blocks in the multiblock copolymers were calculated as follows:

$$
\begin{aligned}
& N_{\mathrm{PB}}=M_{\mathrm{n}} \text { (block copolymer) }{ }^{*} x_{\mathrm{PB}} / M_{\mathrm{n}} \text { (prepolymer) } \\
& N_{\mathrm{SMA}}=N_{\mathrm{PB}}-1 \\
& N_{\mathrm{alt}}=N_{\mathrm{PB}}+N_{\mathrm{SMA}}=2 N_{\mathrm{PB}}-1
\end{aligned}
$$

where $x_{\mathrm{PB}}$ represents the polybutadiene content of the block copolymer and $N_{\mathrm{PB}}$, $N_{\text {SMA }}$, and $N_{\text {alt }}$ represent the average number of polybutadiene blocks, poly(styreneco-maleic anhydride) blocks, and alternating blocks in the block copolymer, respectively. We assume that no active end groups are present in the polymeric iniferter, which is a reasonable assumption, since no SH end groups were detected with FT-IR. Furthermore, we assume that no termination by hydrogen abstraction takes place because of the stabilization of the propagating polymer radicals by the dithiocarbamate counterradicals. So, no matter what transfer reactions will take place, the end blocks of the resulting block copolymer will always be formed by polybutadiene blocks. From the average number of polybutadiene units in the polymeric iniferter $\left(N_{\mathrm{PB}}=2.5\right)$ and using Eq. (3), an average number of four alternating blocks would be expected in the resulting block copolymers. However, the calculated number of blocks is much higher, probably because of intermolecular primary radical termination and chain transfer reactions of the active iniferter groups during polymerization. Block copolymers containing as many as $\mathbf{2 8}$ alternating blocks were obtained this way. The same phenomenon was observed previously by us for polymerizations of styrene with polybutadiene iniferters [36].

GPC measurements showed a single peak for all block copolymers. This is an indication for the absence of nonreacted polymeric iniferter, although some overlap of these peaks might occur. The polydispersity of the block copolymers was around 2.3 , which is fairly low, considering the fact that the polybutadiene blocks of the polymeric iniferter have a polydispersity of 1.65 , and considering the large amounts of intermolecular rearrangements taking place during polymerization. Because this polymerization process involves a thermal iniferter, it cannot be regarded as a living polymerization and therefore lower polydispersities than those obtained by us are not expected for this technique.

In Fig. 4 the SMA block length is plotted as a function of the monomer concentration over the square root of the effective polymeric iniferter concentration (concentration of iniferter groups) since it should be linearly dependent on this ratio. The straight line in Fig. 4 shows that this is indeed the case. So by choosing the right monomer/iniferter ratio, one can prepare block copolymers with the required SMA block lengths.

The system is not well suited for high polybutadiene content block copolymers since the polymerization system would become too viscous at a higher PIn content, and dilution of the system by addition of solvent would lower the propagation rate of the polymerization significantly [36].

The block copolymers synthesized in this work are potential novel efficient compatibilizers for ABS/nylon blends. For compatibilization of nylon-6/polyethyl- 


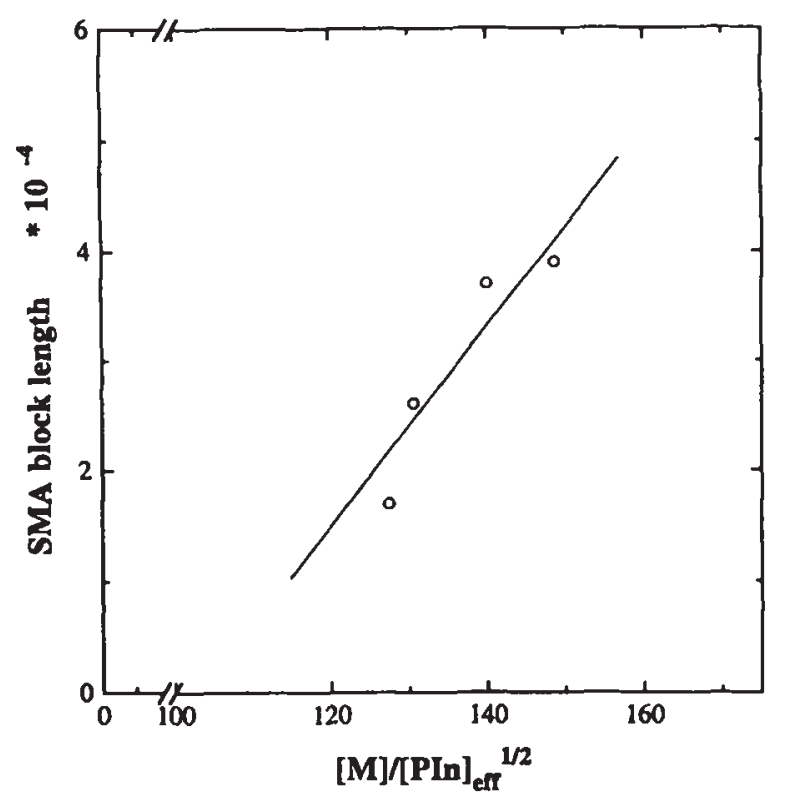
tion.

FIG. 4. Variation of SMA block length with effective polymeric iniferter concentra-

ene blends, block copolymers with a much lower maleic anhydride content (1-2 wt $\%$ ) will be synthesized.

\section{Thermal Behavlor of Segmented PB(SMA-block-PB)n Block Copolymers}

The prepared block copolymers were studied by differential scanning calorimetry. A typical thermogram is shown in Fig. 5. They were found to possess two distinct glass transition temperatures, a $T_{\mathrm{B}}$ at $-80^{\circ} \mathrm{C}$, originating from the polybutadiene blocks, and a $T_{\mathrm{g}}$ of the poly(styrene-co-maleic anhydride) blocks at approximately $125^{\circ} \mathrm{C}$. This is clear evidence that the block copolymers are phase separated. However, at $95^{\circ} \mathrm{C}$ a second transition can be seen. This could be either a mixing $T_{\mathrm{g}}$ or a $T_{\mathrm{g}}$ of short polystyrene sequences.

\section{CONCLUSION}

A polymeric iniferter based on polybutadiene was synthesized and used to initiate the radical copolymerization of styrene and maleic anhydride. In this way segmented block copolymers of polybutadiene and poly(styrene-co-maleic anhydride) were prepared. Compositions and SMA block lengths in the block copolymer could be regulated by varying the polymeric iniferter concentration. MA content of the SMA blocks was regulated by adjusting the monomer feed composition. The system is less appropriate for high polybutadiene content block copolymers. The 


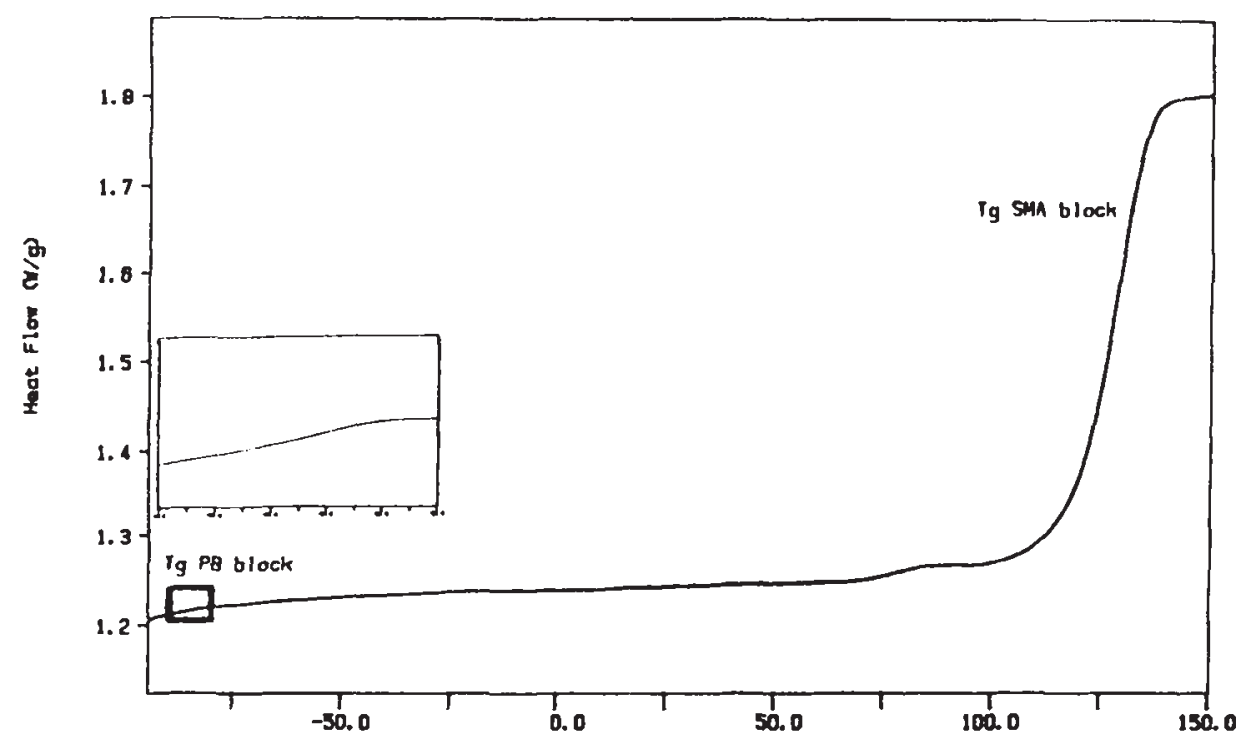

FIG. 5. Thermogram of a segmented PB(SMA-block-PB) ${ }_{n}$ block copolymer.

synthesized compounds appear to be very promising compatibilizers for nylonbased blends, in particular for nylon/ABS blends. This type of block copolymer could also be an efficient compatibilizer for blends of polyethylene and nylon when they are hydrogenated and have SMA blocks containing considerably less maleic anhydride (1-2 wt \%) than the block copolymers reported here. The compatibilizing properties of these new block copolymers are currently being investigated, and we hope to report on this subject in the near future.

\section{REFERENCES}

[1] D. R. Paul and S. Newman (Eds.), Polymer Blends, Academic Press, New York, NY, 1978.

[2] D. R. Paul, J. W. Barlow, and H. Keskkula, Encycl. Polymer. Sci. Eng., 12, 399 (1988).

[3] S. L. Aggarwal, Polymer, 17, 938 (1976).

[4] J. W. Barlow and D. R. Paul, Polym. Eng. Sci., 24, 525 (1984).

[5] R. Fayt, R. Jerome and Ph. Teyssie, Makromol. Chem., 187, 837 (1986).

[6] Ph. Teyssie, Makromol. Chem., Macromol. Symp., 22, 83 (1988).

[7] S. Wu, Polymer, 26, 1855 (1985).

[8] R. Armat and A. Moet, Ibid., 34, 977 (1993).

[9] S. Y. Hobbs, R. C. Bopp, and V. H. Watkins, Polym. Eng. Sci., 23, 380 (1983).

[10] J.-T. Yeh, C.-C. Fan-Chiang and M.-F. Cho, Polym. Bull., 35, 371 (1995).

[11] R. J. M. Borggreve, R. J. Gaymans, and K. M. Eichenwald, Polymer, 24, 78 (1983).

[12] S. Y. Hobbs and M. E. J. Dekkers, J. Mater. Sci., 24, 1316 (1989). 
[13] S. Y. Hobbs, M. E. J. Dekkers, and V. H. Watkins, Ibid., 24, 2025 (1989).

[14] V. J. Triacca, S. Ziaee, J. W. Barlow, H. Keskkula, and D. R. Paul, Polymer, 32, 1401 (1991).

[15] D. V. Howe and M. D. Wolkowicz, Polym. Eng. Sci., 27, 1582 (1987).

[16] R. E. Lavengood and F. M. Silver, SPE, Tech. Pap., 33, 1369 (1987).

[17] M. E. Fowler, D. R. Paul, L. A. Cohen, and W. T. Freed, J. Appl. Polym. Sci., 37513 (1989).

[18] A. R. Padwa and R. E. Lavengood, ACS Symp. Ser., 33, 600 (1992).

[19] O. Majumdar, H. Keskkula, D. R. Paul, and N. G. Harvey, Polymer, 35, 4263 (1994).

[20] E. Gattiglia, A. Turturro, and E. Pedemonte, J. Appl. Polym. Sci., 38, 1807 (1989).

[21] R. J. M. Borggreve, R. J. Gaymans, and A. R. Luttmer, Makromol. Chem., Macromol. Symp., 16, 195 (1988).

[22] J. H. Kim, J. W. Barlow, and D. R. Paul, J. Polym. Sci., Polym. Phys. Ed., 27, 223 (1989).

[23] W. J. Hall, R. C. Kruse, R. A. Mendelson, and Q. A. Trementozzi, ACS Symp. Ser., 229, 49 (1983).

[24] J. Kressler, H. W. Kammer, G. Schmidt-Naake, and K. Herzog, Polymer, 29, 686 (1988).

[25] Y. Aoki, Macromolecules, 21, 1277 (1988).

[26] D.-J. Park, C.-S. Ha, and W.-J. Cho, J. Macromol. Sci.-Pure Appl. Chem., A32, 1317 (1995).

[27] Business Report of Maack Business Services, Multi-client Study 10 (1990).

[28] M. Morimoto, J. Appl. Polym. Chem., 26, 261 (1981).

[29] T. Otsu and M. Yoshida, Makromol. Chem., Rapid Commun., 3, 127 (1982).

[30] T. Otsu, M. Yoshida, and T. Tazaki, Ibid., 3, 133 (1982).

[31] T. Otsu and A. Kuriyama, Polym. J., 17, 97 (1985).

[32] G. Clouet, Polym. Prepr., 33, 895 (1992).

[33] C. P. R. Nair and G. Clouet, Macromolecules, 23, 1361 (1990).

[34] C. P. R. Nair, P. Chaumont, and G. Clouet, J. Macromol. Sci.-Chem. Ed., 27(6), 791 (1990).

[35] C. P. R. Nair, M. C. Richou, and G. Clouet, Makromol. Chem., 192, 579 (1991).

[36] E. Kroeze, G. ten Brinke, and G. Hadziioannou, Macromolecules, 28, 6650 (1995).

[37] E. Kroeze, G. ten Brinke, and G. Hadziioannou, Polymer, In Press.

[38] D. J. T. Hill, J. H. O'Donnell, and P. W. O'Sullivan, Macromolecules, 18, 9 (1985).

[39] B. Klumperman and P. G. Brown, Ibid., 27, 6100 (1994).

[40] P. F. Barron, D. J. T. Hill, J. H. O'Donnell, and P. W. O'Sullivan, Ibid., 17, 1967 (1984).

Received December 30, 1995

Revision received June 15, 1996 